\title{
ISABELLE EBERHARDT (I877-1904) I AURORA BERTRANA (I892-1974): LA LITERATURA DE DUES DONES VIATGERES
}

\author{
ISABEL MARCILLAS PIQUER
}

\begin{abstract}
The article analyses the vision of otherness in the writings of Isabelle Eberhardt (I $877^{-}$ I 904) and of Aurora Bertrana (I892-I974). The I th century expands the possibilities to undertake trips to faraway lands. The incipient European colonialism, the building of the Channel of Suez, steam navigation or the consolidation of a middle class that aspired to expand geographical knowledge, explain the remarkable increase of European travelers to countries of oriental culture. Women also join this wish to travel and, subverting the established patriarchal values, uses the trip as a tool of knowledge of the other and of personal discovery. Accounts of trips offer a vision of the world reformulated from the double marginality of being a woman and the foreigner condition.
\end{abstract}

No hi ha dubte que d'ençà que Antoine Galland, secretari de l'ambaixador del rei portuguès a Turquia, adquirí una cinquantena de manuscrits en àrab, a partir dels quals es realitzà la primera traducció de Les mil $i$ una nits, entre el I704 i el 1717, el món occidental començà a sentir una atracció irrefrenable envers l'oriental; atracció que es traduí en la necessitat de conèixer la cultura pertanyent a l'Orient Pròxim o, dit d'una altra manera, en la necessitat de viatjar-hi. ${ }^{1}$ El viatge assolia l'estatus de pont intercultural, font de coneixement que sovint refermava la identitat del viatger quan aquest s'enfrontava als costums de la terra d'acollida.

Aquesta pot ser una de les raons per les quals sensualitat i fanatisme han estat dos dels trets que s'han atribuït pròdigament al món oriental; tant és així que, sota l'esguard dels occidentals, ambdós han esdevingut estereotips que qualifiquen la civilització musulmana. ${ }^{2}$ No hem de perdre de vista, però, que des del moment que la doctrina islàmica va irrompre, al segle vir, en el panorama de la cristiandat occidental, els musulmans van ser considerats per la majoria dels escriptors europeus com a membres d'una religió força intolerant, un

${ }^{1}$ Amb referència a Les mil $i$ una nits, cal recordar que el seu origen es remunta als segles Ix $\mathrm{i}$ $\mathrm{x}$ i que es tracta d'històries provinents de la tradició oral índia, persa i de l'Âsia Menor; és per aquest mateix motiu, doncs, que no tots els volums recopilen les mateixes històries i que, a més, presenten modificacions diverses segons els traductors. Així, Antoine Galland adaptà el text al públic francès al qual s'adreçava, al temps que Stanley Lane Poole, el i 859, va realitzar una nova traducció que $s$ 'adequava a les necessitats de la societat victoriana anglesa.

${ }_{2}^{2}$ Tot i que en parlarem més endavant, avancem el fet que el llibre d'Aurora Bertrana, en el qual es basa aquest estudi, porta per títol El Marroc sensual i fanàtic. Observem que l'autora catalana fa ús exactament dels dos adjectius a què aquí ens hem referit. 
dels components primordials de la qual era la lascívia. El trànsit de l'edat mitjana al Renaixement, i d'aquest a la Illlustració, no afavorí el canvi de mentalitat dels occidentals, més aviat tot al contrari. La idea que l'home musulmà practicava una sexualitat desenfrenada continuava vigent $i$, si la circumstància s'atribuí, de bell antuvi, a la religió de Mahoma, més tard se'n féu responsable la climatologia africana, persa o aràbiga: Chardin, Montesquieu, Boulanger i, fins i tot, Hegel donaven suport a l'explicació climatològica al temps que, amb les seues teories, contribuïen a desenvolupar l'estereotip de la civilització oriental que, matisada pels corrents orientalistes, arribà fins al segle XIX.

Si ens circumscrivim a l'àmbit català, no podem obviar que, al llarg dels segles, mariners, ambaixadors, militars o comerciants, entre molts d'altres, se sentiren atrets tant pel viatge a l'Orient Pròxim com per les terres que formaven part del litoral nord-africà. Ara bé, per motius preferentment polítics i comercials, no és fins a la segona dècada del segle xix que aquest interès es potencia. Raons com l'incipient colonialisme europeu, la construcció del Canal de Suez, la navegació a vapor o la consolidació d'una classe burgesa que aspirava a ampliar els seus coneixements, expliquen l'augment notable de viatgers catalans als països de cultura oriental (Martín Corrales 83).

Malgrat que, fins aleshores, el més habitual era parlar de viatgers exclusivament en el sentit masculí del mot, la dona europea —en molts casos encara a remolc de l'home - també es va sentir colpida pel desig de viatjar i de conèixer de pròpia mà com era aquell món que traspuava una sensualitat impensable de trobar a Occident. Tanmateix és clar que, de dones, no n’hi hagué moltes que tingueren el coratge d'emprendre un viatge a Orient; la societat demanava al «sexe dèbil» un posat submís al control de l'home, una aparença i una conducta prudents i una llibertat que, en moltes ocasions, es limitava al món de la llar.

En aquest sentit, resulta curiós destacar com Barbara Hodgson, al seu llibre Dreaming of East, on s'aborda el tema del viatge de les dones occidentals a Orient des del segle XviII fins a principis del xx, afirma que aquestes dones emprenien l'aventura oriental a la recerca de llibertat. Hodgson incideix en l'aparent contrasentit que suposa parlar al mateix temps, i com a elements complementaris, de dona, Orient i llibertat; ara bé, és clar que un viatge d'aquesta mena proporcionava a la dona l'ocasió d'escapar a les restriccions a què es veia sotmesa dins de la pròpia cultura i, al mateix temps, li permetia atenuar aquelles llacunes de coneixements que els seus escassos estudis li havien ocasionat.

En cap cas no podem obviar les relacions de jerarquia patriarcal a què la dona s'ha vist sotmesa, adés $i$ ara, en qualsevol àmbit. Es tracta de relacions jeràrquiques que han condicionat el desenvolupament de la dona com a tal $i$ que, per tant, deixaran petja en l'escriptura autobiogràfica. Sempre abocada als marges, el gènere epistolar primer i la narrativa ficcional després han estat els gèneres literaris considerats adients a l'especificitat de la dona. El descobriment del viatge com a eina de coneixement de l'altre i de reconeixement propi la indueix a envair un àmbit social fins al moment reservat als homes. És d'aquesta manera com els relats de viatges resultaran els transmissors d'una visió del món 
reformulada des d'una doble marginalitat, la que s'origina a partir de la condició sexual ostentada i la sorgida a causa de la condició d'estrangera que el viatge implica.

Van ser les dones britàniques les més agosarades a l'hora d'emprendre l'aventura cap a Orient. Així, podem esmentar Sarah Lushington (?-1839), Harriet Martineau (I802-I876), Amelia Cary (I803-I858), Sophia Poole (I804I89I), Margaret Thomas (I843-I 929) o Louisa Jebb (I874-I 927), per exemple. Però les franceses — com Jane Dieulafoy (I8 5 I-I9I6) - , les italianes - com Cristina di Belgiojoso (I 808-I87I) - i, una mica més tard, les espanyoles, com Carmen de Burgos (1867-1932), o les catalanes, com ara M. Antònia Salvà (I 869-1958), o Aurora Bertrana mateix, també sentiren la necessitat de conèixer algun indret oriental.

Algunes de les dones que hem esmentat sentiren la necessitat de deixar constància per escrit de les experiències vitals que el viatge els reportà. La doble marginalitat a què hem fet esment, l'ocasionada d'una banda per la condició sexual de qui escriu i, de l'altra, per l'estatus d'estrangera que ostenta, suposa la necessitat de bastir l'anàlisi de la literatura de viatges escrita per dones a partir d'un marc teòric que permeta copsar-ne la singularitat. Ens interessa particularment la reflexió de Bénédicte Monicat (1996: 29-35), que fa referència a la importància de les consideracions desenvolupades per Albert Memmi i Frantz Fanon amb referència als efectes del colonialisme sobre la cultura de l'altre, ja que influiran, necessàriament, en l'escriptura dels llibres de viatges. Consideracions que resulten extrapolables a l'especificitat de la literatura de viatges escrita particularment per dones.

La reflexió d'Albert Memmi, autobiogràfica, se centra en l'opressió exercida pel fort sobre el dèbil. En el seu cas, es tracta d'una opressió per raons religioses i culturals. Memmi, jueu de la Tunísia subordinat a la tutela francesa, analitza la complexitat de la pròpia posició com a integrant de la collectivitat jueva, cosa que el diferencia de l'àrab al temps que l'apropa a l'opressor, el colonitzador. Memmi es veu obligat, doncs, a moure's en un espai ambivalent que el convida a identificar-se tant amb la imatge de l'oprimit com amb la d'aquell que oprimeix. Aquesta ambivalència li permet constatar amb una certa objectivitat la situació d'opressió a què s'enfronten els dèbils:

Nous savions déjà que tous les opprimés se ressemblaient; le Colonisé, le Juif, le Pauvre, la Femme, par-delà leurs traits individuels et leurs histoires spécifiques, ont un air de parenté: tous, ils subissent un joug, qui laisse des traces analogues dans leurs âmes et imprime un gauchissement similaire dans leurs conduites. (24)

Si la situació de Memmi, com a jueu, el porta a establir una analogia comportamental entre els oprimits, qualsevol que en siga la causa de l'opressió, el raonament de Fanon en aquest sentit tampoc no ens pot deixar indiferents $i$ ens ajudarà, així mateix, a analitzar la psicologia que transmet la mirada de la dona viatgera. Al seu treball Peau noire, masques blancs (1952) Fanon analitza com 
el sentiment d'inferioritat propiciat en l'home de pell negra, a causa de les estructures polítiques, econòmiques i culturals dominants, desencadena tot un procés d'assimilació, d'identificació amb l'home blanc que el mateix Fanon ha qualificat com «l'écroulement du Moi». Contra aquesta mena d'enfonsament de la pròpia personalitat només es pot lluitar a través de la identificació amb l'altre. D'aquesta manera, així com la raça negra només pot revalorar-se mitjançant la identificació amb la blanca, la dona solament adquireix vàlua com a tal en el moment que ocupa espais reservats culturalment a l'àmbit maculí. En paraules de Monicat: «En se rapprochant de ce qui est valorisé par l'expérience masculine, la voyageuse tente de parvenir à la reconnaissance de sa propre valeur mais pour ce faire elle doit s'interdire d'être femme» (Monicat 3I).

És en aquest context que hem de situar la vida i l'escriptura de les dues autores objecte d'aquest estudi, Isabelle Eberhardt i Aurora Bertrana, dues dones viatgeres i coneixedores de l'Orient que materialitzaren les seues experiències, els seus objectius i el seus punts de vista envers el món oriental mitjançant escrits de caire autobiogràfic que en testimonien les vivències. Ambdues, viatgeres per territoris colonitzats per la pròpia cultura, no per la pròpia condició de gènere, ofereixen una mirada particular de l'altre, una perspectiva que sovint incideix en l'espai privat, en el desig de ser posseides per la cultura que descobreixen, més que no pas de posseir-la, com seria el cas dels seus homòlegs masculins.

En aquest sentit, no podem estar-nos d'esmentar l'expressió exploradores socials defensada per Mary Louise Pratt en fer referència a les dones viatgeres. En tant que exploradores, les dones s'acaren a un món nou, recorren un indret, un país, amb la intenció de descobrir què hi ha. En tant que socials, les dones indaguen entorn de les relacions humanes que s'estableixen entre els diferents estaments d'una societat. Per tant, des d'aquest punt de vista, la mirada de les viatgeres suposa una font de coneixement que no parteix de bell antuvi de la voluntat de possessió ni de domini típicament masculines, sinó més aviat d'una capacitat d'emoció, fins i tot d'acceptació, d'allò que és nou. Justament és això el que trobem en l'escriptura de viatges de Bertrana i Eberhardt, l'anàlisi dels textos de les quals ens serveix, d'una banda, per a establir-ne una similitud d'interessos adduïbles a la condició de dona tot i que, de l'altra, aquests interessos es concreten en opcions vitals divergents.

Isabelle Eberhardt, filla d'aristòcrates exiliats russos, naix a Ginebra el I 877; als vint anys Eberhardt es veu arrossegada pel desig de la mare, Nathalie de Moërder, de viatjar a Annaba, a la costa algeriana. Un cop allà, la mare mor passats uns mesos i és soterrada al cementiri musulmà sota el nom de Fatma Mannoubia. Des de la seua arribada a terres algerianes, mare i filla són seduïdes per l'islam, per l'atracció del que s'anomena mektoub: una creença sense reserves en el destí, marcada per la resignació com a virtut principal (Delacour-Huleu io). Eberhardt va viure en tot moment amb la mirada tombada cap a Orient i les diverses anades i tornades que va protagonitzar al llarg de la seua curta existència no van fer més que estimular el seu desig d'integrar-se en la societat 
oriental, cosa que va intentar fins i tot adoptant la personalitat d'un home, Mahmoud Saadi; amb aquest nom va signar molts dels seus escrits, amarats sempre d'intimisme $\mathrm{i}$, en ocasions, d'una malenconia gairebé indescriptible que presagiava un final tràgic. ${ }^{3}$ Ben aviat, Eberhardt va demostrar la seua vocació literària; el I 895 van aparèixer les seues primeres publicacions a la Nouvelle revue moderne de París, sota el pseudònim de Nicolas Podolinsky. Posteriorment, les seues experiències serviren de base a textos com País d'arena: relats algerians $\mathrm{i}$ Jasmina $i$ altres narracions, publicats pòstumament. A partir del I902, va convertir-se en collaboradora regular en diaris de l'Alger i va participar en l'aparició de l'Akhbar, periòdic públic en àrab i en francès, de tendència liberal. Se n'ha dit que estava «touchée par la grâce» i se l'ha comparada amb d'altres poetes considerats transgressors, com ara Rimbaud, Artaud, Cocteau o Pasolini (Delacour-Huleu 8).

Com hem comentat adés, si hi ha un tret, però, que caracteritze amb més intensitat l'obra de la joveníssima Eberhardt és l'intimisme. D'intimisme amara cada descripció de la vida beduïna i musulmana, una vida que ella respecta i admira i en la qual lluita per ésser acceptada com un membre més de la comunitat. I d'intimisme també, i d'amor, en són plens els escrits de caràcter epistolar que adreçava als tres homes més importants de la seua vida: Augustin, el germà; Ali Abdul Wahab, còmplice intellectual, i Slimène Ehni, l'home que va triar com a parella sentimental. Resulta curiós observar que Eberhardt donava una importància especial a les cartes que escrivia; ho demostrava en recomanar als seus destinataris que les conservaren: «Conserve ces quelques lettres où je réussis parfois à mettre un peu de mon âme» (Delacour-Huleu i 5 ). De la mateixa manera que ho va demostrar quan, abans de marxar cap a Ain Sefra, va confiar al seu amic Victor Barrucand les cartes que havia escrit tant al seu germà com a Slimène Ehni.

Dissortadament, l'any 1904, quan en comptava vint-i-set, Eberhardt mor, mentre es trobava a casa seua, soterrada pel fang a causa de la crescuda d'un riu. Fou un dels vint desapareguts en la catàstrofe d'Ain Sefra. La seua correspondència, nombrosa, $\mathrm{i}$ altres testimonis de l'atzarosa $\mathrm{i}$ intensa vida d'Isabelle Eberhardt es conserven al fons que porta el seu nom a Ais de Provença.

Per la seua banda, Aurora Bertrana, nascuda a Girona el I 892 i filla de l'escriptor modernista Prudenci Bertrana, és un bon exemple del model d'intellectual femenina occidental de principis de segle xx. Era una lletraferida colpida també pel desig de viatjar i per l'anhel de conèixer cultures alienes, cultures que li permetrien comparar la seua posició de dona europea amb la d'aquelles altres dones que formaven part de mons considerats, en aquell moment, exòtics. Així, l'any 1926 viatja a Tahití, amb el seu marit, on residí durant

${ }^{3}$ Cal notar, però, que aquesta malenconia estava en relació amb el tarannà de la literatura europea pertanyent al «fin du siècle», que amarava els textos d'allò que s'anomenà ennui i que es traduïa en una mena de fascinació pel misteri i pel misticisme religiós. La cultura musulmana oferia a Isabelle Eberhardt aquests elements. 
tres anys. Fruit d'aquesta estada, fou el seu llibre Paradisos oceànics, publicat l'any I930, que li deparà un gran èxit com a escriptora i la féu mereixedora dels qualificatius de viatgera i aventurera, que ja no l'havien d'abandonar al llarg de la seua vida. De l'experiència tahitiana sorgí també el recull de contes Peikea, princesa canibal $i$ altres contes oceànics, publicat l'any 1934, al temps que l'autora colllaborava en revistes de l'època com ara Mirador o La Humanitat. Sovint, la seua presència era reclamada per oferir conferències en centres excursionistes o en associacions diverses on les aventures del viatge, contades per una dona, resultaven font de curiositat.

El 1935 Aurora Bertrana viatjà tota sola al Marroc; ens deixa constància d'aquest viatge a través del volum El Marroc sensual i fanàtic, llibre de viatges de caire autobiogràfic on l'autora reflecteix el seu pas per diverses ciutats del Marroc i les impressions suscitades pel coneixement de tipus i costums, en especial aquells que fan referència al món de la dona musulmana. També diverses cròniques publicades a $L a$ Publicitat i les mateixes Memòries de l'escriptora certifiquen l'experiència que, com a dona occidental, visqué en terres musulmanes. ${ }^{4}$

Parlem, doncs, de dues dones escriptores, viatgeres i seduïdes per Orient. Tanmateix, si bé ens proposem d'establir els punts de contacte entre ambdues autores, no podem deixar d'esmentar aquells elements que, salvant la distància temporal, divergeixen en els seus textos de caire autobiogràfic; una divergència que, sens dubte, troba l'origen en la mateixa biografia d'Eberhardt i Bertrana i que, no obstant això, permet d'inserir l'obra d'aquesta última dins del corrent orientalista de l'època preconitzat per Edward Said, segons els trets que aquest mateix autor reconeix per als orientalistes:

Individualitat forta, simpatia i identificació intuïtiva amb l'Orient, un sentit zelosament preservat de la missió personal a l'Orient, excentricitat cultivada i una desaprovació final a l'Orient. Per a ells, l'Orient consistia en la seva experiència directa, peculiar, que havien obtingut. En ells, l'orientalisme i la pràctica efectiva de manipular l'Orient van rebre la forma final europea. (Said 225)

Al mateix temps, Said confirma que aquests individualistes no eren acadèmics i que no pertanyien en cap aspecte a la comunitat oficial i professional dels

${ }^{4}$ Amb referència als motius pels quals Aurora Bertrana decidí viatjar al Marroc, només hi ha un capítol al seu llibre de viatges, El Marroc sensual i fanatic, on es justifique aquesta decisió. El capítol porta per títol «L'autor a la recerca d'una culpa» i narra les persecucions de què fou objecte l'escriptora per part de la policia colonial en terres del Protectorat espanyol. En aquest sentit, Bertrana, amb el deix d'ironia que li era habitual, explica amb aquestes paraules com va confessar la seua innocència al policia que la interrogava i quin era el motiu de la seua presència al Marroc: «Fou un segon altament dramàtic. Jo acabava de descobrir mil possibilitats de brillar en el camp aventurer $\mathrm{i}$ audaç de la política, alhora que descobria la meva insignificança aclaparadora. ¡Dissortada de mi! $¡ \mathrm{Ni}$ comunistes, ni separatistes, ni jesuïtes, ni francmaçons no m’havien triat com a emissària! Solament la publicitat m'havia fet l'honrós, però modest encàrrec, de distreure-li els llegidors. Entre sobresalts financers i polítics, les meves cròniques havien d'ésser per a ells el que és l'orxata o l'ombra d'un arbre per al suat caminant" (El Marroc I 22). 
estudis orientalistes. Malgrat tot, es parla d'una expertesa conseqüència de certes circumstàncies mundanes, determinades tant per la tradició com per les institucions o per la voluntat o la intel-ligència específica amb què cadascú articula l'experiència pròpia d'Orient. La posició d'home erudit blanc permet a l'orientalista formular una sèrie de veritats generals extretes a partir d'una visió de l'Orient des d'una suposada posició de superioritat que pretén el domini de qualsevol parcel-la que configure la categoria d'oriental, ja es tracte de cultura, de religió, de societat, etc. Entrem així en una mena de cercle viciós en què l'oriental queda descrit a través d'una sèrie de categories reductives que, pel fet d'estar construïdes des del punt de vista occidental, impedeixen l'oriental de reconèixer-s'hi, tot i que, d'altra banda, contribueixen a l'autoafirmació i reconeixement de la categoria d'occidental. Amb l'anàlisi dels textos triats podrem observar com Aurora Bertrana pren aquest posicionament.

Per al desenvolupament d'aquest estudi comparatístic, hem considerat adient utilitzar el volum que porta per títol Los diarios de una nómada apasionada - un aplec de quatre diaris íntims d'Eberhardt que comprenen des del gener de l'any i 900 fins a l'abril del I904, any en què va morir-, i El Marroc sensual i fanàtic de Bertrana, tenint en compte que, tot i que aquest últim és una literaturització de l'estada al Marroc de l'autora catalana, apareix reproduït, gairebé fil per randa, tant en el seu primer volum de memòries, Memòries fins al 1935 , com en els articles que n'aparegueren a La Publicitat.

El viatge d'Eberhardt a Annaba, el i 897, amb la mare, converteix de bell antuvi la jove escriptora en una nòmada apàtrida. ${ }^{6} \mathrm{El}$ seu tarannà, fort i valent, li fa menysprear aquelles dones que no gosen contravenir els valors i les actituds que l'època els imposa. Així ho deixa entendre al seu diari íntim, on afirma:

En mi s'estan desenvolupant l'energia més obstinada, la més invencible, i la rectitud de cor, dos qualitats que aprecie per sobre de totes les coses i, ai, massa estranyes en una dona. Amb elles, i quatre mesos al desert, molt probablement en primavera, estic segur[a] 7

s La traducció al català dels diferent fragments que reproduïm al llarg de l’article és nostra, a partir de l'edició castellana Los diarios de una nómada apasionada, Barcelona, Planeta, 2008.

${ }^{6}$ Feia temps que Isabelle Eberhardt manifestava el seu interès a viatjar a terres africanes. El I896, deprimida perquè el germà havia marxat a la Legió estrangera i havia estat destinat a Saïda, a Algèria, decideix escriure, dibuixar i estudiar més que mai. És així com, encoratjada a ampliar els seus coneixements en llengua àrab i turca, escriu a Abou Naddara —un jueu egipci exiliat a París des del i 878 , fundador de la revista Le Journal d'Abou Naddara - tot demanant-li consell per comprar un diccionari de turc. Entre altres coses, Eberhardt afirma en aquesta carta: «vull esforçarme a recórrer i veure els països orientals. He estudiat sola, sense mestre, $\mathrm{i}$ he après poc...» (Errera 33). Louis David, un fotograf amic de la família - $\mathrm{i}$ autor d'algunes de les fotografies que avui es conserven d'Isabelle Eberhardt - proposà a Nathalie de Moërder, la mare, i a la mateixa Isabelle de llogar-los una casa de què disposava a Bône, Algèria. Fou així com, sis mesos més tard, ambdues dones emprengueren un viatge que marcaria les seues vides.

7 L'edició dels diaris d'Isabelle Eberhardt a partir de la qual treballem avisa que la jove escrivia tant emprant la forma masculina com la femenina, motiu pel qual els traductors han optat per unificar criteris i usar solament la forma femenina. Particularment, pensem que es tracta d'una decisió poc encertada tenint en compte que Eberhardt havia estat educada com un noi, vestia sovint 
de convertir-me en algú fort... i, per això mateix, podré aconseguir tard o d'hora el fi sagrat de la meua vida. (Eberhardt, Los diarios de una nómada 23)

Resulta revelador comprovar que, tot i la trentena d'anys que separen els escrits de les autores que aquí analitzem, ambdues creuen en el viatge com a eina instructiva; un viatge, però, que s'allunye de les comoditats i que esdevinga element forjador d'un caràcter sòlid, indestructible davant de les adversitats. Amb referència a això, Aurora Bertrana afirma:

Perquè el viatge sigui profitós en el sentit educació cal, per damunt de tot, emprendre'l sense diners ... Conec una infinitat de senyores i senyoretes que han viatjat per tot Europa, $i$ fins per Amèrica, $i$ continuen sent tan ignorants $i$ ineducades com abans ... Deixem doncs de banda aquesta mena de viatges que no són els que a mi m'interessen. Dels que jo vull parlar-vos és dels altres, dels que han deixat en mi un rastre profund, dels que han canviat la meva naturalesa mateixa, equilibrant-me i donant-me fortitud per a afrontar la vida i facultats per a assaborir la petita part de felicitat que em correspon en aquest món. (Bertrana «El viatge») $)^{8}$

Les paraules d'Aurora Bertrana confirmen que, tant per a ella mateixa com per a Eberhardt, les vicissituds experimentades a causa de la rudesa d'un viatge amb escassos mitjans econòmics, $i$ amb gairebé nulles comoditats, les han convertides en el que són, dones fortes capaces de valorar el que una cultura aliena els pot oferir i capaces, per tant, d'ocupar posicions reservades a l'home fins aquells moments.

Ara bé, els anys que transcorren des que Eberhardt viatja al desert, en repetides ocasions, fins que ho fa l'autora catalana, l'any 1935 , suposen un canvi notable en l'experiència viscuda. La literatura de finals del segle xIx utilitzava el desert com a escenari sobre el qual planava la llegenda, la petja dels beduïns, el cant dels camellers, les caravanes dels guerrers o l'omnipresència de la mort (Litvak 83); una atmosfera entre tràgica i fantàstica que encara es respira als escrits d'Eberhardt. Comprovem-ho amb les seues pròpies paraules:

En caure el sol, vaig reprendre el camí de l'Oued. Vaig veure en la duna grisenca com corria la sorra igual que onades blanques d'un oceà silenciós. El cim d'una gran duna punxeguda, orientada cap a l'oest, semblava fumejar com un volcà. El sol, primer groc, envoltat de vapors sulfurosos, es va anar acolorint amb els apoteòsics tints de cada vespre...

com un noi i se la considerava posseïdora de trets andrògins. Ella mateixa decidí signar molts dels seus escrits amb pseudònims masculins $i$, un cop installada a terres algerianes, com ja hem comentat, adoptava sovint la personalitat d'un home, Mahmoud Saadi. Al mateix temps, hem d'enllaçar aquesta situació amb la teoria defensada per Monicat, i esmentada anteriorment en aquest treball, segons la qual la dona només adquireix vàlua pròpia en el moment en què ocupa posicions reservades al gènere masculí.

8 Aquest és un fragment de la conferència pronunciada per Aurora Bertrana a l'Ateneu Barcelonès el dia i i de novembre de I930, dedicada al Club Femení d’Esports. Porta per títol «El viatge educatiu $\mathrm{i}$ instructiu». El mecanoscrit es conserva al Fons Bertrana, classificat amb el número $\mathrm{I}$. Hem introduït al text les esmenes corresponents per tal d'adaptar-lo a la normativa actual. 
També ahir, abans de muntar a cavall, vaig sentir les lamentacions que entre els àrabs anuncien una mort... (Eberhardt, Los diarios de una nómada 78-79)9

La visió que Aurora Bertrana mostra del desert continua oferint al lector algun dels trets que caracteritzaven els escrits dels orientalistes europeus, com ara la inclemència del sol: «jo estic mig atontada», diu, «la reverberació del sol, forma com núvols gelatinosos, a través dels quals mils i mils de puntets enlluernadors fereixen cruelment les nines». ${ }^{10} \mathrm{Amb}$ tot, no es pot obviar que Bertrana desmitifica de bell antuvi el desert quan afirma:

Començo per dir que, per a mi, l'encís del Desert ja no existeix. L'han destruït els automòbils i els aeroplans, com han destruit altres coses. La grandiositat terrorífica del Sàhara es fon amb la substitució del dromedari pel vehicle a motor, com la facilitat de transports fa desaparèixer la dolcesa consoladora de l'oasi ...

I l'Oasi, que pareixia un petit paradís als pobres caminants, llagats i malaltissos, víctimes de la immensitat roenta dels sorrals, avui és una banal i pueril visió de rierols i palmes, per a qui baixa d'un automòbil o d'un avió, algunes hores després d'abandonar una ciutat urbanitzada. (Bertrana, Butlletí del Centre Excursionista 99) ${ }^{\text {II }}$

Però, més enllà de l'encís aclaparador del desert experimentat per Eberhardt i del desencís patit per Bertrana a causa de l'arribada de la civilització al món oriental, ambdues escriptores es veuen abassegades per la climatologia a la qual s'han d'enfrontar. Així, Eberhardt, quan el mes de juliol del ı 900, des de Marsella estant, prepara el seu viatge a terres algerianes, reconeix: «No solament em preocupa el treball, sinó també les qüestions higièniques; hauré de reaccionar contra la involuntària fluixedat que produeix el clima del Sàhara a l'estiu» (Eberhardt, Los diarios de una nómada $5 \mathrm{I}$ ).

En tant que a El Marroc sensual i fanàtic, quan relata l'estada a Tetuan, Aurora Bertrana observa:

Quan les altes muntanyes de la Djelaba s'ennuvolaven o la calor queia abassegadora damunt de la ciutat, i l'hora esdevenia melangiosa, L. V. i jo, enfonsats en els seients de braços del casino, romaníem aclaparats i indecisos.

-Què farem? - deia pausadament l'escriptor. I jo sentia que, féssim el que féssim, no ens salvaríem d'aquella apatia climàtica. (Bertrana, El Marroc 44)

9 Aquest fragment es correspon a l'entrada del segon diari d'Isabelle Eberhardt del dia is 8 d'agost de 1900 .

10 Aquestes paraules formen part d'un article titulat «La meva visió del Sàhara», que Aurora Bertrana va escriure per al Butlletí del Centre Excursionista de Catalunya l'any I 936.

${ }^{11}$ Resulta significatiu observar com Caren Kaplan (8I) fa referència al tema del desert en l'obra de Baudrillard, Amèrica. Baudrillard proposa una nova estètica del desert mitjançant una contrametàfora de la vida i confirma així la multiplicitat d'interpretacions de les quals pot ser objecte. En definitiva, Kaplan suggereix la reconstrucció d'una mateixa realitat segons l'individu guie la pròpia recerca, afirmació que apliquem als textos d'Eberhardt i de Bertrana. 
Tanmateix el clima, que tradicionalment servia als orientalistes per a explicar alguns dels trets de l'home musulmà —en particular aquells relacionats amb la poligàmia i el desig sexual-, no fou motiu suficient per a desencoratjar ni Eberhardt primer, ni Bertrana després. ${ }^{{ }^{2} 2}$ Ambdues persistiren en el seu desig de viatjar a Orient tot convertint el viatge en font d'instrucció per a elles mateixes, $i$ els escrits que se'n derivaren en eina de coneixement també per als lectors.

L'escriptura es transforma així en un element de representació de l'alteritat i, com a tal, en instrument de poder. Com afirma Kaplan, ja siga a través de la narració d'una experiència o de la descripció d'una determinada realitat, la paraula suposa l'expressió d'un punt de vista parcial que mai no està exempt de manifestar relacions de poder. Però ni Bertrana ni Eberhardt escriuen conscients de la força de l'escriptura en aquest sentit; la primera s'hi aboca com a necessitat professional i la segona, com a procés vital.

La urgència de reflectir mitjançant la paraula escrita les experiències viscudes, Eberhardt la manifesta en alguns fragments del seu diari íntim, gairebé com si es tractés d'una grafòmana. La nit del i 8 de juliol de i900, en planificar el seu pròxim viatge al continent africà, diu:

De camí, trauré notes cuidadoses del que vaja aprenent i també d'allò que em vaja impressionant. La travessia per mar, després l'Argèlia italiana i l'Oued Rir", serà un viatge interessant, pintoresc — primera cosa a redactar només hi arribe.

Un cop allí, als oasis, prendre nota de tot, començar per visitar-ho tot i fer un plànol detallat amb les anotacions més completes possibles. Després, obrir un diari literari del temps que estiga allí... Si a la tardor avancem cap al Marroc, seguiré, com és normal, aquella direcció, però no deixaré en cap moment de prendre notes minucioses. (Eberhardt, Los diarios de una nómada 55)

Per la seua banda, Aurora Bertrana, en la «Justificació» a El Marroc sensual i fanàtic, explicita amb aquestes paraules com aborda la tasca literària:

Durant la confecció d'aquesta obra, no de viatges sinó d'impressions viatgeres, he dubtat sovint entre amagar l'anècdota personal o ofrenar-vos-la neta i clara, sincera i absoluta. Ha guanyat la darrera de les opinions ...

Totes les meves pretensions literàries es limiten a la pintura dels paisatges i dels monuments vistos pels meus ulls profans, curiosos $\mathrm{i}$ àvids de viatgera inlassable, $\mathrm{i}$ a la descripció dels tipus que s'han creuat al meu camí, dibuixats a través de les meves reaccions sentimentals i intellectuals. (El Marroc 20)

Però, tot i les paraules de l'escriptora catalana, ni els paisatges, ni encara menys els monuments, no eren el centre d'interès de les seues observacions. Per contra, els tipus, homes o dones - particularment aquestes últimes-, així com

${ }^{12}$ Vegeu Crónicas sarracinas de Juan Goytisolo, on l'autor al.ludeix a la climatologia com una de les causes per les quals s'atribuïa a la cultura oriental un comportament sexual immoral per als occidentals. D'altra banda, en aquest treball, Goytisolo esmenta també l'obra d'Aurora Bertrana $E l$ Marroc sensual i fanàtic, remarcant-ne els estereotips orientalistes als quals fa referència el títol. 
els costums, captaven tota la seua atenció. Tot i que no siga el tema d'aquest estudi, no podem obviar el particular interès d'Aurora Bertrana per la dona musulmana. Abans que qualsevol altra cosa, en viatjar al Marroc, el seu objectiu era apropar-se al món de les dones i, d'una manera o d'una altra, s'ha de dir que ho aconseguí; visità prostíbuls, algun harem, la presó de dones, les dones d'un baixà, la cabila on habitaven diverses dones pertanyents a una família de posició humil i, fins i tot, fa extensiva al lector la història d'una fakiha o santa. Així, doncs, no se li pot negar el mèrit d'intentar-ho amb uns resultats prou acceptables, tot i que, anés on anés, sempre era considerada una rumia, una estrangera. La diferència entre ella $\mathrm{i}$ Eberhardt rau en el fet que l'autora catalana emprengué la tasca de coneixement de l'altre amb certes prevencions ocasionades pels estereotips imperants $i$, en conseqüència, del viatge se'n derivà l'autoafirmació de la pròpia identitat - com era el cas de la majoria d'europees que s'aventuraven en aquest tipus de viatge- Contràriament a això, Isabelle Eberhardt s'apropà a la cultura de l'altre amb un desig precís d'integrar-s'hi totalment i, per tant, de ser acceptada com un membre més de la comunitat musulmana. Si parem esment a un tret tan superflu com l'aspecte físic que ambdues dones mostraven o adoptaren en arribar a terres nord-africanes, aquesta divergència d'intencions encara es palesa amb més intensitat.

Diu Aurora Bertrana a El Marroc sensual i fanàtic tot fent referència a la seua pròpia aparença física: «Per al musulmà corrent, una dona carregada d'uns estris tan poc femenins com estilogràfica, papers i kòdak, que mostra, impúdica, cames, braços i cara, que beu cervesa i que freqüenta homes, és capaç de qualsevol cosa. Les possibilitats malfactores, diablesques, desorientadores i perilloses d'aquesta desvergonyida fembra li semblen incalculables» (I 8).

I, més endavant, fent referència a un àpat celebrat a casa d'un ministre musulmà al qual fou convidada, la cronista encara comenta:

Fumàvem i bevíem recolzats en coixins. Jo conversava amb l'estudiant turc sobre política femenina, quan els meus ulls distrets s'enlairaren devers les altes finestres enreixades que s'obrien sobre el pati central. A cada obertura hi havia un grapat de dones, ben apilades. ¡Enmig de l'embolcall de llurs blancs haics, els ulls negres vorejats de cahol esguardaven curiosos i engelosits aquella rumia, vestida de fil, lluint cames i braços, fumant, xerrant, discutint amb els homes! (56)

L'actitud d'Isabelle Eberhardt és ben diferent; els seus diaris ho palesen quan, per exemple, explica: «Després d'una breu trobada amb Eugène a la meua habitació, ell se'n va anar, i jo vaig marxar sola a explorar. Però el meu barret era un destorb, em separava de la vida musulmana. Aleshores vaig tornar, em vaig posar el meu fes i vaig sortir novament en direcció a la Djemaa-el-Kebira» (Los diarios de una nómada 6I). O quan diu: «Asseguda en un racó, amb les robes àrabs que feien que em sentira còmoda, vaig cantar i tocar el tamborí fins ben entrada la nit» (Los diarios de una nómada I66).

D'aquests testimonis deduïm que, tot i que ambdues dones viatgen al nord d'Àfrica amb el desig d'obtenir-ne el coneixement de l'altre, les posicions que 
adopten resulten ben bé oposades: mentre Bertrana actua amb una finalitat ben definida, com a periodista, com a detectiva $i$, fins i tot, com a jutgessa de la cultura oriental, Eberhardt només hi busca una sincera integració.

Pel que fa al sexe, el comportament de totes dues també resulta divergent. Aurora Bertrana juga a treure partit de la seua condició de dona. Al llarg de la lectura d'El Marroc sensual i fanàtic, observem com la periodista se serveix del propi sexe per atraure l'atenció del lector occidental, el qual - atesa la sensualitat i el fanatisme que envolten, prototípicament, el món musulmà- tindrà per segur que l'escriptora ha hagut d'enfrontar-se a tot tipus de dificultats o perills derivats del seu agosarat viatge. Vegem un exemple de com Aurora Bertrana exposa al lector la dificultat que afegeix la condició de dona sola:

A Europa — descartant les puntes que tenen veïnatge amb l'Àfrica一, la nostra instrucció, adquirida en collegis, instituts o universitats mixtos, el nostre tracte freqüent amb homes, des del començament de la vida, ens posen en condicions de conèixer on rauen els veritables esculls de les relacions socials entre els dos sexes, i aprenem aviat a deslliurar-nos-en. Al Marroc, aquest saber navegar en mars intersexuals no us serveix de res, per tal com allí la dona sola no trobarà zones navegables sinó en aigües purament sexuals. (19)

No hem d'oblidar, però, que la cronista insisteix en diverses ocasions en el fet que els perills o les molèsties més enutjoses li van arribar sovint per part dels mateixos europeus. Així conta, irònicament, la seua arribada a un oasi on hi havia installat un destacament militar:

No tot, al món, són deserts i camins impracticables, marxes forçades, set, polls i disciplina. També hi ha oasis ... I de tant en tant (¡oh benaurança!) arribarà una dona. La dona, amb tota la grandiositat, l'atractiu i la poesia del mot. jElla!

Ella, en aquest cas, era jo, per dissort ... Els setze parells d'ulls ingenus dels colonials tenien una eloqüència inequívoca ... A través de llurs esguards més i més lluminosos, més i més insistents, jo em descobria. Vaig començar per veure els meus braços nus, la meva escolladura, les floretes i fulles vermelles, grogues i verdes del meu vestit de fil i els cabells negres amb algun fil blanc i el meu rostre lassat d'un llarg i calorós viatge. Però ells ho veien tot divinament perfecte, àdhuc luxós, elegant, preparat... (El Marroc 235)

La posició d'Isabelle Eberhardt, pel que fa al seu sexe, no té res a veure amb la que es trasllueix de les paraules d'Aurora Bertrana; la seua conducta permet intuir, més aviat, una mena de renúncia a la condició sexual. El fet de ser dona, lluny de resultar un atractiu per a un possible públic lector, esdevé per a Eberhardt un entrebanc a l'hora de recórrer espais prohibits o a l'hora d'ésser acceptada com un membre més de la comunitat. Les indumentàries dels homes, els costums dels homes o els espais que freqüenten els homes, tot això és el que més s'adiu al tarannà inquiet i agosarat de la jove Eberhardt. Ella mateixa, en una carta que dirigí al director de La Dépêche Algérienne el 7 de juny de I90 i que apareix reproduida al costat dels seus diaris personals, afirma: 
El cap de la delegació de l'Oued, capità $\mathrm{M}$. Couvert, home de molt alta vàlua intellectual i molt lliurat al seu servei, va tenir, durant sis mesos, l'ocasió de comprovar de visu que no se'm podia retreure res, amb excepció d'una immensa originalitat, un gènere de vida valent per a una noia, però totalment inofensiu... i no va jutjar que la meua preferència de l'haik en comptes de la faldilla i de les dunes en comptes de la llar domèstica poguera ser perillosa per a la seguretat pública a la seua delegació. (Los diarios de una nómada 156$)^{13}$

I encara més endavant, el 23 de juliol del mateix any, ressenya en el seu diari: «En el moment que em vestiré de dona, trobaré sense problemes algun treballet mentre espere una cosa millor» (Los diarios de una nómada 179), paraules que confirmen el fet que ocultar la identitat sexual era una circumstància habitual per a l'escriptora, qui, d'aquesta manera, se situava gairebé al marge de la societat. Es tractava d'un gust per la marginalitat de què sempre havia fet mostra, fins i tot quan vivia amb la família a Ginebra, potser induïda per la mateixa excepcionalitat dels seus. ${ }^{14}$ No resulta menys cert que el caràcter d'Eberhardt no li permet mostrar-se tal com és; en el seu primer diari, redactat a Càller, amb data de l'ı de gener de I900, afirma: «Per a la galeria, lluïsc la suposada màscara del cínic, del perdut i del que a mi tant em fa...» (Los diarios de una nómada I6). Aquest no és tampoc el cas de l'escriptora catalana, a qui agrada mostrar-se natural, espontània i, fins i tot, ser exemple per a altres dones.

Ambdues autores coincideixen, però, en la valoració que fan de la dona europea installada en territori africà; en aquest sentit, tant Eberhardt com Bertrana transmeten gairebé un sentiment de rebuig, dirigit a les europees, avalat per la descripció d'actuacions d'apatia i de manca d'interès per la societat que els dóna acollida. Així, installlada a Arzila, Aurora Bertrana comenta:

Les dones europees de la burgesia són les úniques que, per mitjà de les relacions administratives i comercials dels marits, podrien acudir de tant en tant als harems, per xafardejar una estona (xafardeig ple d'interès, que els permetria l'estudi psicològic de les germanes musulmanes). Però a les dames europees tot això les atrau molt poc. S'estimen més criticar entre elles i acudir als cinemes, reclosos i pudents, on projecten films de fa

${ }^{13}$ La redacció d'aquesta carta, dirigida al director de La Dépêche Algérienne, té a veure amb un atemptat que Isabelle Eberhardt patí a Behima el 29 de gener de i 90 I. Sembla que la tribu dels Tidjani, per motius religiosos, no estava a favor de la presència d'Eberhardt. Un membre d'aquesta tribu va atacar l'escriptora mentre aquesta estava de viatge amb l'Elimam d'una tribu rival, els Kadryas. Abd Allah ben Mohammed va intentar assassinar Eberhardt d'un cop de sabre. Una corda per a estendre la roba situada damunt del seu cap va fer que el desenllaç de l'atemptat no fóra fatídic, tot i que va haver d'estar hospitalitzada al llarg de tres setmanes. A causa de l'enrenou ocasionat per l'atemptat, Isabelle Eberhardt rebé un avís d'expulsió, que va resultar fals, però que la va fer partir cap a Marsella (Errera 196).

${ }_{14}$ Cal tenir en compte que la mare, casada amb un general i senador rus, Paul Carlovisky de Moërder, per raons no gaire clares, marxa de Rússia amb els seus tres fills i amb l'home que els fa de preceptor, Alexandre Trophimowsky. Posteriorment, naix Isabelle Eberhardt, però Trophimowsky no la reconeix com a filla, motiu pel qual Eberhardt porta el nom de la mare. Eberhardt passa la infantesa a Meyrin (Ginebra), en una mansió que portava per nom «La Villa Neuve»; sembla que allà la família rebia tot tipus de personatges: revolucionaris, anarquistes, perseguits. Fou justament això, però, i els coneixements que li transmeté Trophimowsky, el que permet considerar com a particular i marginal la infantesa viscuda per l'autora. 
deu o dotze anys, enmig dels crits espantosos de la quitxalla, del fum i de les escopinades dels homes (El Marroc 57).

Per la seua banda, Eberhardt, durant una estada a Batna, confessa: «Aquí és l'avorriment total, el trist avorriment de viure entre éssers sense intellligència, en aquesta horrorosa mediocritat $i$ enmig de la indiscreció d'unes femelles indignes del nom d'éssers humans» (Jiménez I 3 ). Totes dues escriptores denuncien el comportament de les representants europees femenines; elles, que gaudeixen de major llibertat que les «germanes musulmanes», no saben aprofitar-la, cosa tan reprovable, o pitjor encara, que la submissió a la qual aquelles es veuen abocades. Això no obstant, l'amor que Isabelle Eberhardt professa a Slimène fa que accepte les normes socials que contemplen el sotmetiment de la dona a l'home i, així, en una de les entrades del seu diari afirma: «He d'imposar-me a mi mateixa el que per naturalesa m'és més difícil: la submissió, encara que certament amb límits, sense arribar al rebaixament, la submissió que edulcore la nostra vida en comú... Resumint, és necessari que faça per la meua banda un gran esforç per reformar el meu caràcter i fer-lo més suportable» (Los diarios de una nómada $\mathrm{I} 33$ ).

Sorprenentment, així mateix, el fet de viure reclosa sembla perdre importància si es tracta d'un acte empès per l'amor d'Eberhardt cap a Slimène Ehni, a qui també dóna l'apelllatiu afectuós de Rouh: «Poc importa la misèria, molt real ara, i la vida enclaustrada entre les dones àrabs... Beneïda siga fins i tot la dependència absoluta de Rouh que tindré d'aquí en endavant... Però el que em tortura i em fa la vida gairebé insuportable és estar separada d'ell» (Los diarios de una nómada I I6).

D'aquesta manera, comprovem com és l'amor cap a un home aquell que doblega la voluntat sempre ferma i el tarannà inquiet d'Eberhardt, que confessa, íntimament, acceptar la submissió i el tancament a què són sotmeses les dones àrabs. Però, tant submissió com enclaustrament són dos mots que no s'adiuen en absolut al caràcter de l'escriptora catalana que, abans de res, es considera una dona lliure. Així, després de la visita que realitzà a una presó de dones a Xauen, Bertrana afirma: «Per a una dona lliure com jo, les petites culpes d'aquestes pobres presoneres resulten una lliçó d'humilitat, de resignació i de modèstia» (El Marroc I06). També la visita a l'harem del ministre musulmà la fa sentir marejada a causa de l'ambient reclòs que s'hi respira i la sensació de llibertat se n'apodera en eixir-ne: «Mitja hora després era al carrer, respirant l'aire pur de les properes muntanyes, contemplant l'horta verda i groga que s'estén fins al mar i seguint entendrida un núvol blanc que volava devers l'Occident damunt la Mediterrània amiga...» (El Marroc 54). Els mots de la periodista denoten una complicitat amb Occident que mai no podrà establir amb certs costums del món oriental; aquesta impossibilitat d'establir lligams — predeterminada psicològicament per aquell sentiment de superioritat de l'occidental influït pels tòpics orientalistes-, al costat de la resistència que ofereix la cultura musulmana a l'hora de donar a conèixer detalls referents a la vida 
íntima o familiar, és el que fa que Aurora Bertrana arribe a aquesta insòlita conclusió: «He cregut descobrir que les dones musulmanes no tenen ànima. És a dir que manquen en absolut de vibracions espirituals. Les tradicions, els principis alcorànics, la superioritat social masculina, tot conspira contra el desenvolupament de l'esperit femení musulmà». is

Tot i això, d'una manera o d'una altra, fou el coneixement directe, l'experiència personal viscuda dins la mateixa cultura musulmana, el que permeté a Aurora Bertrana confrontar els tòpics orientalistes preestablerts amb la veritable situació de la població al Marroc. És en aquest sentit que, en el llibre d'impressions viatgeres redactat per la cronista, no podem obviar algunes al.lusions relatives al colonialisme, tant espanyol com francès.

Per a Bertrana «un dels fenòmens curiosos per a qui travessa el Marroc amb els ulls oberts, el cor net i l'esperit lliure, és el contrast que provoquen l'Orient i l'Occident» (El Marroc 87). Tot i que l'autora reconeix que els occidentals han posat ordre i neteja en el caos que caracteritza les ciutats al Marroc, troba que és d'agrair que encara queden «ciutats netament musulmanes, francament $\mathrm{i}$ incorruptiblement moresques», en les quals es pot assistir al que ella considera «un dels espectacles més emocionants del món: l'heroica i formidable resistència de l'Orient contra l'Occident» (El Marroc 87). A més, la periodista catalana es queixa de la incapacitat administrativa colonial dels espanyols, els quals considera indisciplinats, individualistes $i$ anàrquics, per contraposició als francesos, segons l'autora «veritables i únics representants de l'Occident al Marroc»; ara bé, cal incidir en el fet que Bertrana, tot i reconèixer l'admiració que sent per la tasca realitzada en el protectorat francès, manifesta posseir principis antiinvasius i anticolonials.

A propòsit del colonialisme, resulta interessant comprovar que ja l'any I900, durant la seua estada a l'Oued, Algèria, la jove Eberhardt afirma que la societat àrab es troba desorganitzada i viciada a causa del contacte amb els estrangers, tant allí com en les ciutats més grans. Així mateix, després de l’atemptat patit per l'escriptora el 30 de gener de I90I, Eberhardt es queixa de la dependència burocràtica del Sàhara respecte a França i, més endavant, en el seu diari, manifesta la manca de caràcter dels pobles usurpats als autòctons i edificats sota el manament del protectorat francès. Eberhardt, igual que Bertrana, manté una mirada crítica cap a aquells que considera els seus compatriotes, ara els algerians: com més s'atansa al món de la política algeriana, més desencisada se sent. ${ }^{16}$ Tot amb tot, no podem ignorar que, l'any I903, Eberhardt i el general Lyautey es van conèixer $i$, curiosament, de bell antuvi van simpatitzar. Arran

is Aquesta citació es correspon a un fragment de la conferència sense datar d'Aurora Bertrana que porta per títol «L'Amor al viatge». La conferència es troba mecanografiada i amb correccions de puny i lletra de la mateixa autora al Fons Bertrana, de la Universitat de Girona. Al començament del text, l'autora diu recordar una conferència pronunciada en aquell mateix ateneu, cosa que fa pensar que es tracta de l'Ateneu Barcelonès.

${ }^{16}$ Conegut a través d'Edmond Charles-Roux, Isabelle $d u$ désert, annex de fotografies inclòs entre les pàgines $752 \mathrm{i} 753$. 
d'aquesta amistat, l'escriptora es va poder moure amb absoluta llibertat pel territori algerià i va poder dur la vida que desitjava com a dona independent. Resulta obvi que aquesta circumstància no hauria estat possible sense la intervenció colonial francesa; en aquest sentit, doncs, cal remarcar l'ambigüitat del posicionament d'Eberhardt pel que fa a la qüestió colonial: si bé la critica i la rebutja, també se n'aprofita.

Kaplan, en Questions of Travel, esmenta que la crítica feminista euroamericana ha expandit el concepte de solidaritat femenina basat en l'existència de valors i aspiracions compartides entre les dones; confirma també, fent allusió a Woolf, que l'habitació que els és pròpia s'ha eixamplat de la llar a l'esfera pública (6I), i d'això n'és testimoni la pràctica del viatge per part del gènere femení. Els escrits d'Eberhardt i Bertrana en són una mostra. Comptat i debatut, tant l'una com l'altra, amb gairebé una trentena d'anys de diferència, tot i pertànyer a països i a classes socials diferents, amb mentalitats i educacions també ben diferents, perceben l'aventura del viatge cap al món oriental com un mètode d'enriquiment personal. Ambdues es consideren tan capaces com qualsevol home de poder afrontar les inclemències climatològiques, la rudesa del desert $\mathrm{o}$ els entrebancs administratius sorgits, sovint, a causa del seu sexe. No obstant això, les reaccions suscitades a causa de l'estranyament de la nova cultura són diferents. Bertrana es referma com a dona occidental, tot i que critica la tasca colonial dels seus compatriotes. Eberhardt se sent altament atreta per la cultura i la religió islàmica, fins al punt que es reconeix musulmana. Ambdues experimenten la necessitat d'escriure les seues vivències, adés amb un caràcter íntim, adés amb un afany divulgador, mitjançant cròniques periodístiques o conferències. Finalment, tant l'una com l'altra viuen el viatge com un espai i com un temps de llibertat que els permet trencar dues classes diferents d'estereotips: d'una banda, aquells que estan relacionats amb la mitificació d'Orient $i$, de l'altra, aquells que tenen a veure amb els patrons comportamentals de la dona com a tal. És així com aquestes consideracions ens permeten cloure l'anàlisi comparatística tot assumint les nocions de viatge i escriptura com a instruments configuradors de la identitat de la dona de principis del segle xx, però també com a mecanismes d'una construcció diferenciada de l'alteritat.

ISABEL MARCILLAS PIQUER UNIVERSITAT D'AlACANT

\section{REFERÈNCIES}

Bertrana, Aurora. El Marroc sensual i fanàtic. Barcelona: Columna, 2000. -. «El viatge educatiu i instructiu». Document núm. I Fons Bertrana. Girona: Universitat de Girona, 1930. 
-. «L’amor al viatge». Document núm. 6 Fons Bertrana. Girona: Universitat de Girona, sense datar.

—. «La meva visió del Sahara.» Butlletí del Centre Excursionista de Catalunya 490 (1936): 99-IOI.

-. Memories fins al 1935. Barcelona: Pòrtic, I973.

Charles-Roux, Edmonde. Isabelle du désert. París: Grasset-Fasquelle, 2003.

Delacour, Marie-Odile i Jean-René Huleu, ed. «Présentation». Écrits intimes d'Isabelle Eberhardt. París: Payot, I991. 7-17.

Eberhardt, Isabelle. Écrits intimes. Ed. a cura de Marie-Odile Delacour i Jean-René Huleu. París: Payot-Rivages, 2003.

- Los diarios de una nómada apasionada. Trad. Adolfo García Ortega. Barcelona: Planeta, 2008.

-. País de arena. Relatos argelinos. Ed. i trad. a cura d'Immacula Jiménez Morell. Madrid: Ediciones del Mediterraneo y del Oriente, 2000.

Errera, Eglal. Isabelle Eberhardt. Barcelona: Circe, I990.

Fanon, Frantz. Peau noire, masques blancs. París: Seuil, I952.

Goytisolo, Juan. Crónicas sarracinas. Barcelona: Seix Barral, I989.

Hodgson, Barbara. Rêve d'Orient. Les Occidentales et les voyages en Orient, xviIIe-début du xxe siècle. Trad. Pierre Saint-Jean. París: Seuil, 2005.

Jiménez Morell, Immaculada. «Introducción». Eberhardt, Isabel. País de Arena. Relatos argelinos. Madrid: Ediciones del Oriente y del Mediterráneo, 2000. VII-XVI.

Kaplan, Caren. Questions of travel. Durham: Duke UP, 1996.

LiTvaK, Lily. «Exotismo del oriente musulmán fin de siglo». Awraq XI (1990): 73-103.

Martín Corrales, Eloy. «Un siglo de viajes y viajeros catalanes por tierras del Norte de África y Próximo Oriente (I 833-1939): peregrinos, nostálgicos y colonialistas». Illes $i$ Imperis 8 (2006): 83-I I I.

Mеммі, Albert. L'bomme dominé. París: Gallimard, 1968.

Mills, Sara. Discourses of Difference: An Analysis of Women's Travel Writting and Colonialism. Londres: Routledge, I99I.

Monicat, Bénedicte. Itinéraires de l'écriture au féminin. Voyagueses du Ige siècle. Amsterdam: Rodopi, I996.

PRATT, Mary Louise. Imperial Eyes: Travel Writing and Transculturation. Londres: Routledge, I992.

SAID, Edward W. Orientalisme. Identitat, negació i violència. Vic: Eumo, I99I. 